\title{
Detailed Precision of Computed Tomography Angiography Compared to Invasive Angiography in Different Coronary Vessels: Overestimate, Underestimate, or Concordance?
}

\author{
TM Haykal', Elen', Celly A Atmadikoesoemah', Abhirama N Putra', Andrew Parlautan', \\ Wendy M Saragih', Manoefris Kasim
}

'Department of Cardiology and Vascular Medicine, Faculty of Medicine, Universitas Indonesia.

RS Jantung dan Pembuluh Darah Harapan Kita, Jakarta, Indonesia.
Background: Quantitative analysis of stenosis lesions by Computed Tomography angiography (CTA) show good correlation with Invasive Coronary Angiography (ICA) examination. However, detailed precision whether CTA overestimate or underestimate have not been explored thoroughly.

Objectives: This research is performed to analyze the precision of CTA compared to ICA.

Materials \& Methods: There are 195 patients examined by both CTA and ICA from October 2014 until December 2015 in our hospital. CTA was analyzed by a team of cardiovascular imaging cardiologists. Quantitative grading of stenosis was determined visually using 20 I 4 Society of Cardiovascular Computed Tomography (SCCT) guidelines classification. Quantitative measurement of stenosis during ICA was classified with the same criteria so that it can be comparable. The final comparison of both tests was classified as concordance, overestimate and underestimate.

Results: Lesion of stenosis was found in 573 coronary vessels. Coronary vessels are significantly associated with detailed precision of quantitative analysis comparison in CTA and ICA. LM coronary stenosis quantification from CTA is predominantly overestimate (concordance in $6 \%$ vessels and overestimate in $75.9 \%$ vessels), while stenosis analysis by CTA in other major coronary vessels is spread without conspicuous domination $(\mathrm{p}<0.00 \mathrm{I})$. Sensitivity, specificity, PPV, and NPV of CTA to detect obstructive lesion (stenosis $\geq 50 \%$ ) found by ICA is $81.4 \%, 80.4 \%, 73.9 \%$, and $86.3 \%$, respectively (780 vessels).

Conclusions: Degree of stenosis in LM is predominantly overestimate by CTA. The precision of stenosis grading in CTA in different coronary vessels is not the same.

(Indonesian J Cardiol. 20 I8;39:7-I4)

Keywords: Computed Tomography angiography (CTA), Invasive coronary angiography (ICA), Precision. 


\title{
Presisi Computed Tomography Angiography Terhadap Invasive Angiography pada masing-masing Pembuluh Koroner: Overestimate, Underestimate, atau Concordance?
}

\author{
TM Haykal', Elen', Celly A Atmadikoesoemah', Abhirama N Putra', \\ Andrew Parlautan', Wendy M Saragih', Manoefris Kasim'
}

Latar Belakang: Analisis kuantitatif lesi stenosis pada pembuluh koroner menggunakan modalitas Computed Tomography Angiography (CTA) memiliki korelasi yang baik dengan pemeriksaan Invasive Coronary Angiography (ICA). Namun, presisi CTA terhadap ICA masih belum tereksplorasi dengan baik. Terutama dari sisi apakah CTA menunjukkan presisi yang overestimate atau underestimate.

Tujuan: Penelitian ini dilakukan untuk menganalisis presisi CTA terhadap ICA dalam mendeteksi lesi stenosis pada pembuluh koroner.

Metode Penelitian: Terdapat 195 pasien yang diperiksa menggunakan CTA dan ICA sejak Oktober 2014 hingga Desember 2015 di RS Jantung dan Pembuluh Darah Harapan Kita, Jakarta. Analisis kuantitatif CTA dilakukan oleh tim kardiolog pencitraan kardiovaskular. Klasifikasi derajat stenosis ditentukan secara visual menggunakan pedoman dari Society of Cardiovascular Computed Tomography (SCCT) 2014. Analisis kuantitatif lesi stenosis dari pemeriksaan ICA diklasifikasikan menggunakan pedoman yang sama sehingga keduanya dapat diperbandingkan. Data hasil perbandingan kedua modalitas diklasifikasikan sebagai concordance, overestimate dan underestimate.

Hasil Penelitian: Lesi stenosis ditemukan pada 573 pembuluh koroner. Pembuluh koroner yang berbeda secara signifikan berhubungan dengan perbandingan klasifikasi analisis semi-kuantitatif CTA dan ICA. Pembuluh koroner LM terutama menunjukkan lesi dengan kategori overestimate $(75.9 \%)$. Sementara analisis stenosis pada pembuluh koroner lainnya tidak menunjukkan perbedaan yang mencolok ( $\mathrm{p}<0,001)$. Sensitivitas, spesifisitas, PPV, dan NPV CTA dalam mendeteksi lesi koroner obstruktif (stenosis $\geq 50 \%$ ) terhadap ICA adalah sebesar $81.4 \%$, $80.4 \%, 73.9 \%$, dan $86.3 \%$ (780 pembuluh kroner).

Kesimpulan: Analisis stenosis semi-kuantitatif pada LM terutama adalah overestimate berdasarkan pemeriksaan CTA. Presisi analisis perbandingan derajat stenosis CT angiografi pada setiap pembuluh koroner tidak sama.

(Indonesian J Cardiol. 2018;39:7-14)

Kata Kunci: Computed Tomography angiography (CTA), Invasive coronary angiography (ICA).

Departemen Kardiologi dan Kedokteran Vaskular, Fakultas Kedokteran Universitas Indonesia, RS Jantung dan Pembuluh Darah Harapan Kita, Jakarta, Indonesia.

\section{Correspondence:}

dr. TM Haykal, Department of Cardiology and Vascular Medicine, Faculty of Medicine, Universitas Indonesia.

E-mail: tm_haykal@yahoo.com

\section{Pendahuluan}

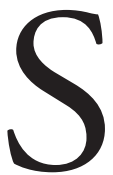

eiring dengan berkembangnya teknologi, deteksi lesi obstruktif penyakit jantung koroner tidak hanya dapat dilakukan dengan pemeriksaan angiografi koroner invasif (Invasive Coronary Angiography / ICA). ${ }^{1-2}$ Pemeriksaan pencitraan kardiovaskular lain juga dapat diandalkan, salah satunya adalah Computed 


\section{Haykal TM dkk: Presisi Computed Tomography Angiography Terhadap Invasive Angiography pada masing-masing}

Pembuluh Koroner: Overestimate, Underestimate, atau Concordance?

Tomography Angiography (CTA). ${ }^{3-5}$ Berbagai studi menunjukkan bahwa CTA memiliki angka sensitivitas dan spesifisitas yang baik dalam mendeteksi penyakit jantung koroner. ${ }^{1,5-10}$ Selain itu, analisis kuantitatif lesi stenosis oleh CTA menunjukkan korelasi numerik yang cukup baik dengan analisis kuantitatif lesi stenosis yang didapatkan dari pemeriksaan ICA. ${ }^{11-12}$ Namun demikian, studi perbandingan antara kedua modalitas pemeriksaan tersebut memprediksi bahwa presisi CTA hanya sekitar 25\% dalam memprediksi lesi stenosis pembuluh koroner secara kuantitatif pada ICA. ${ }^{3}$

Pada tahun 2014, Society of Cardiovascular Computed Tomography (SCCT) menyusun rekomendasi penggunaan klasifikasi semi-kuantitatif untuk menggambarkan derajat stenosis koroner. Klasifikasi ini menerjemahkan derajat persentase stenosis menjadi 6 kategori. Klasifikasi ini telah rutin digunakan dalam berbagai penilaian yang menggunakan modalitas CTA. ${ }^{3}$ Rincian klasifikasi semi-kuantitatif ini dapat diperhatikan pada Tabel 1.

Tabel 1. Rekomendasi penilaian derajat stenosis ${ }^{3}$

0-Normal: tidak ditemukan plak dan tidak ada stenosis luminal
1-Minimal: plak dengan stenosis $<25 \%$
2-Ringan: stenosis 25\% sampai $49 \%$
3-Sedang: stenosis $50 \%$ sampai $69 \%$
4-Berat: stenosis $70 \%$ sampai $99 \%$
5-Oklusi

Hingga saat ini, belum ada data apakah analisis stenosis secara semi-kuantitatif dari pemeriksaan CTA memberikan gambaran presisi yang baik bila dibandingkan dengan ICA. Eksplorasi lebih lanjut dapat memberikan wawasan bahwa analisis stenosis pembuluh koroner berdasarkan pemeriksaan CTA memberikan hasil yang overestimate atau underestimate terhadap pemeriksaan ICA. ${ }^{8}$ Penelitian ini bertujuan untuk membandingkan presisi analisis stenosis antara CTA dan ICA berdasarkan klasifikasi semikuantitatif.

\section{Metode}

Penelitian ini menggunakan desain potong lintang (cross-sectional). Penelitian ini dilakukan pada populasi pasien dengan penyakit jantung koroner yang telah terkonfirmasi memiliki setidaknya 1 lesi obstruktif berdasarkan pemeriksaan CTA dan selanjutnya menjalani ICA. Penelitian ini dilakukan sejak bulan Oktober 2014 sampai dengan Desember 2015 di RS Jantung dan Pembuluh Darah Harapan Kita (RSJPDHK). Penentuan perbedaan presisi karakteristik koroner yang diperiksa dilakukan dengan analisis berdasarkan pembuluh darah koroner yang terlibat (vessel-based analysis).

Teknologi CTA yang digunakan adalah 128-slice MDCT scanner (Hitachi Scenaria 128-slice) dengan software TeraRecon Inc dan menggunakan standar operasional prosedur yang seragam. Analisis CTA dilakukan oleh tim kardiolog pencitraan kardiovaskular dengan metode penilaian kuantitatif secara visual dan diklasifikasikan secara semi-kuantitatif sesuai pedoman SCCT 2014. ${ }^{3}$ Analisis ICA dilakukan oleh tim kardiolog intervensi kardiovaskular yang juga menggunakan metode analisis kuantitatif secara visual dan juga diklasifikasikan menggunakan pedoman yang sama dari SCCT 2014. Pada kedua modalitas, definisi lesi obstruktif adalah bila didapatkan lesi stenosis $\geq 50 \%$. ${ }^{6-10}$

Dua analisis statistik yang dilakukan pada penelitian ini adalah untuk menilai akurasi dan presisi pemeriksaan CTA terhadap ICA. Akurasi CTA ditentukan dengan penilaian sensitivitas, spesifisitas, nilai prediktif positif (PPV), dan nilai prediktif negatif (NPV). Akurasi CTA didasarkan pada terdeteksinya lesi obstruktif pada kedua modalitas pemeriksaan. Analisis statistik presisi CTA terhadap ICA didasarkan pada perbandingan hasil analisis semikuantitatif sesuai pedoman SCCT 2014. ${ }^{3}$ Selanjutnya dilakukan perbandingan antara kedua analisis semikuantitatif dari kedua pemeriksaan tersebut dan akan didapatkan data perbandingan kategorikal. Kategori yang dimaksud adalah: 1) Concordance (sesuai), apabila analisis stenosis semi-kuantitatif dari kedua modalitas menunjukkan klasifikasi yang sama; 2) Overestimate (berlebihan), apabila data analisis semikuantitatif CTA menunjukkan klasifikasi lebih berat bila dibandingkan dengan analisis semi-kuantitatif ICA; dan 3) Underestimate (kekurangan), apabila data analisis semi-kuantitatif CTA menunjukkan klasifikasi lebih ringan bila dibandingkan dengan analisis semi-kuantitatif ICA. ${ }^{8}$ Pengelompokan ini dilakukan berdasarkan klasifikasi derajat stenosis secara semi-kuantitatif, sehingga tidak terdapat perbedaan dalam bentuk angka antara masing-masing kelompok. Data klasifikisi kategorikal tersebut akan diuji secara statistik. 


\section{Hasil}

Jumlah subjek dalam penelitian ini adalah sebanyak 195 pasien dengan usia rata-rata 59 tahun dan mayoritas merupakan laki-laki (66,2\%). Total sampel yang dianalisis sejumlah 780 pembuluh darah koroner yang terdiri dari LM (Left main coronary artery), LAD (Left anterior descending coronary artery), LCX (Left circumflex coronary artery), dan RCA (Right coronary artery). Keseluruhan pembuluh darah tersebut dapat dianalisis dengan baik tanpa gambaran artefak. Terdapat 573 lesi stenosis yang ditemukan di berbagai pembuluh koroner. Data karakteristik dari seluruh subjek penelitian dapat diperhatikan pada Tabel 2.

Tabel 2. Karakteristik Pasien

\begin{tabular}{lc}
\hline Karakteristik & N (\%) pasien* \\
\hline Jenis kelamin & $129(66.2)$ \\
Laki-laki & $66(33.8)$ \\
Perempuan & $59.19 \pm 9.79$ \\
Usia (tahun) & \\
Klasifikasi skor kalsium & $120(61.5)$ \\
$0-400$ & $75(38.5)$ \\
$>400$ & \\
Pembuluh koroner dengan lesi stenosis & $83(14.5)$ \\
LM & $193(33.7)$ \\
LAD & $140(24.4)$ \\
LCX & $157(27.4)$ \\
RCA & \\
Adanya plak dengan kalsifikasi & $447(78.0)$ \\
Terdapat plak terkalfisikasi & $126(22.0)$ \\
Tidak terdapat plak terkalsifikasi & \\
Jumlah pembuluh yang terlibat & $31(15.9)$ \\
Satu pembuluh koroner & $50(25.6)$ \\
Dua pembuluh koroner & $114(58.5)$ \\
Tiga pembuluh koroner & $83(14.5)$ \\
Lesi pada LM &
\end{tabular}

* Variabel numerik direpresentasikan sebagai mean \pm standar deviasi LM: Left main coronary artery, LAD: Left anterior descending coronary artery, LCX: Left circumflex coronary artery, RCA: Right coronary artery.

Pemeriksaan CTA dalam penelitian ini memiliki sensitivitas $81,4 \%$, spesifisitas $80,4 \%, P P V 73,9 \%$, dan $N P V$ 86,3\% terhadap ICA dalam mendeteksi lesi obstruktif di pembuluh koroner. Data akurasi ini didasarkan pada analisis berdasarkan pembuluh darah koroner (vessel-based analysis) dengan besar sampel sebesar 780 pembuluh koroner.

Analisis statistik untuk menentukan presisi CTA dalam menentukan lesi stenosis secara semi-kuantitatif menunjukkan perbedaan yang bermakna pada pembuluh koroner yang berbeda.Lesi stenosis yang ditemukan pada LM dari pemeriksaan CTA terutama merupakan lesi overestimate (75,9\%). Sementara lesi stenosis $\mathrm{LAD}$ terutama terklasifikasikan sebagai concordance $(44,5 \%)$. Tidak ada perbedaan menonjol antara analisis stenosis di pembuluh RCA dan LCX. Analisis statistik chi-square menunjukkan hasil signifikan dengan nilai $p<0,01$. Rincian persebaran data presisi di setiap pembuluh koroner dapat diperhatikan pada Tabel 3. Beberapa contoh hasil pemeriksaan CTA dan ICA dengan klasifikasi concordance, overestimate dan underestimate dapat diperhatikan pada Gambar 1, Gambar 2, dan Gambar 3.

Tabel 3. Perbandingan penilaian derajat stenosis antara CTA

\begin{tabular}{ll} 
dengan ICA pada pembuluh koroner $(\mathrm{p}<0,01)$ \\
\hline Lesi Koroner \& Klasifikasi Semi-Kuantitatif & $\mathrm{N}(\%)$ \\
\hline LM & $5(6.02)$ \\
Overestimate & $63(75.90)$ \\
Underestimate & $15(18.07)$ \\
LAD & \\
Concordance & $86(44.56)$ \\
Overestimate & $75(38.86)$ \\
Underestimate & $32(16.58)$ \\
LCX & \\
Concordance & $31(22.4)$ \\
Overestimate & $66(47.14)$ \\
Underestimate & $43(30.71)$ \\
RCA & \\
Concordance & $45(28.66)$ \\
Overestimate & $65(41.40)$ \\
Underestimate & $47(29.94)$ \\
\hline
\end{tabular}

Pada beberapa penelitian mengenai presisi CTA terhadap ICA yang telah dilakukan sebelumnya, keberadaan plak berkalsifikasi selalu ditekankan sebagai penyebab analisis stenosis yang tidak akurat. ${ }^{8}$ Hal ini diperkirakan dapat menjadi suatu penyebab perbedaan hasil analisis pada pembuluh koroner. Namun berdasarkan analisis statistik lanjutan pada penelitian ini ditemukan bahwa keberadaan plak berkalsifikasi tidak mempengaruhi akurasi analisis stenosis $(p=0,102)$. Dari semua pembuluh koroner yang dianalisis, lesi plak berkalsifikasi terdapat pada $78 \%$ pembuluh koroner. Pada LM, dimana lesi dominan tergolongkan sebagai overestimate, plak berkalsifikasi dapat diidentifikasi pada proporsi 
Haykal TM dkk: Presisi Computed Tomography Angiography Terhadap Invasive Angiography pada masing-masing Pembuluh Koroner: Overestimate, Underestimate, atau Concordance?

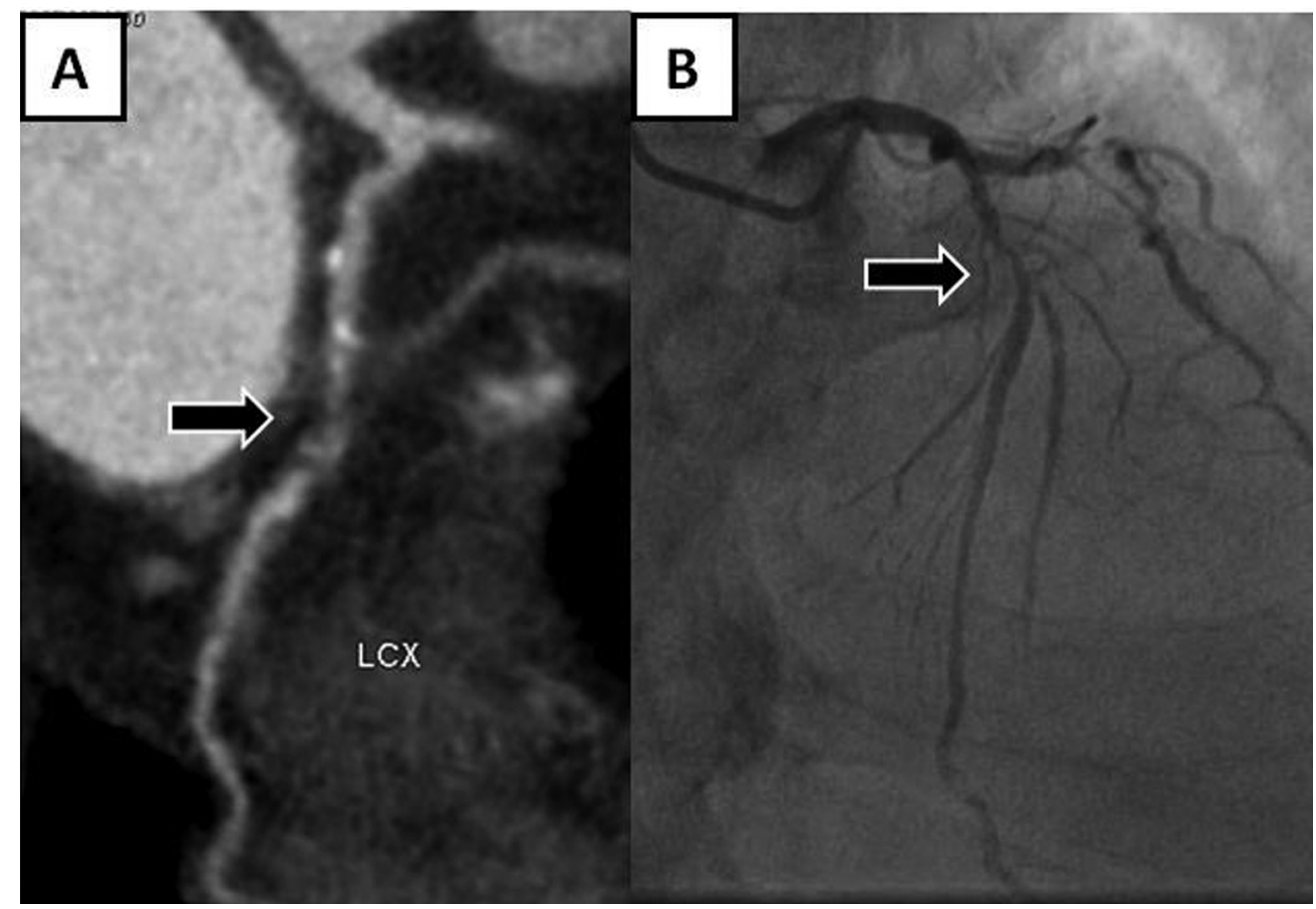

Gambar 1. Analisis stenosis concordance pada laki-laki usia 62 tahun pada LCX. A: Lesi stenosis dari CTA dengan derajat stenosis berat (90\%).

B: Lesi stenosis dari ICA dengan derajat stenosis berat (95\%)

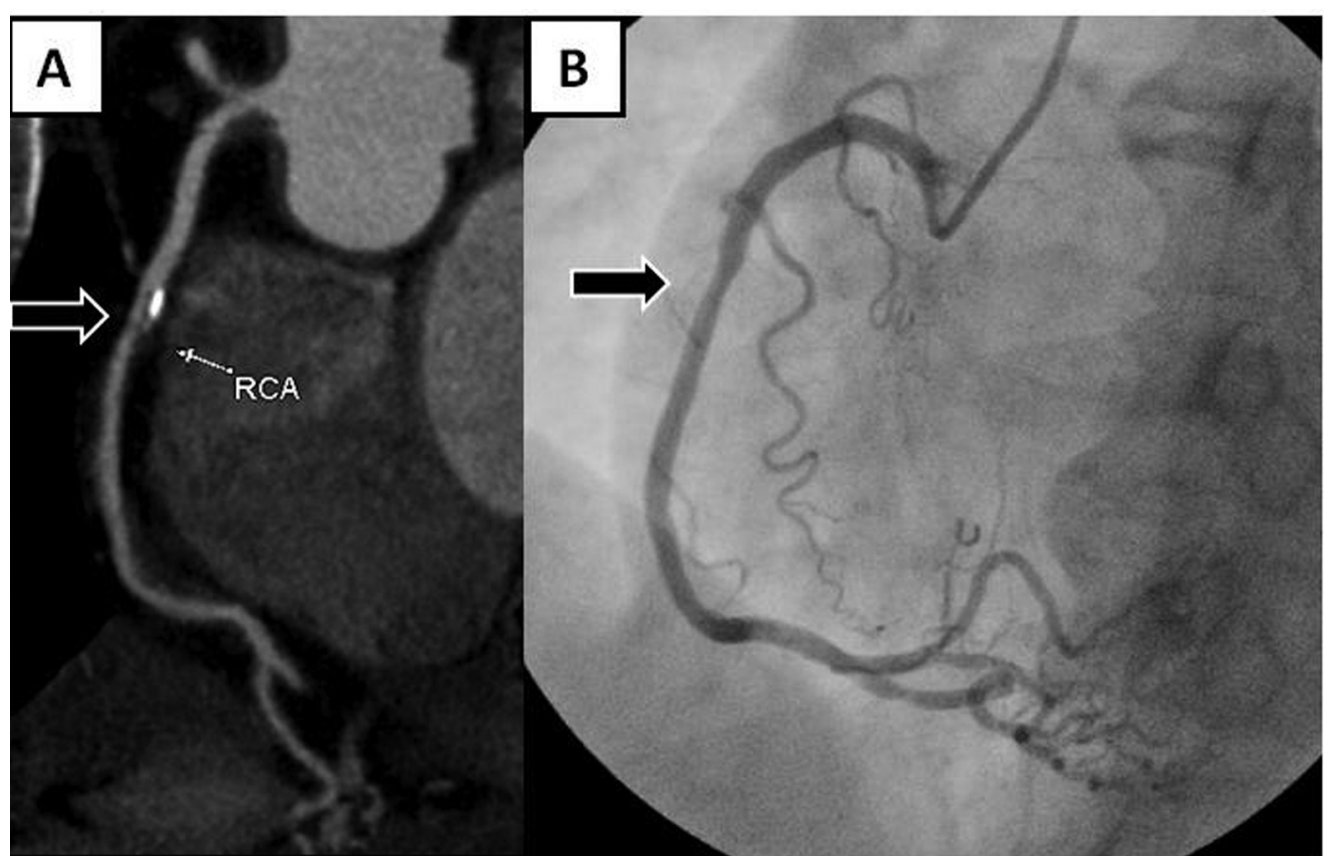

Gambar 2. Analisis stenosis overestimate pada perempuan usia 50 tahun di RCA. A: Lesi stenosis dari CTA dengan derajat stenosis sedang (60\%).

B: Lesi stenosis dari ICA dengan derajat stenosis ringan (40\%). 


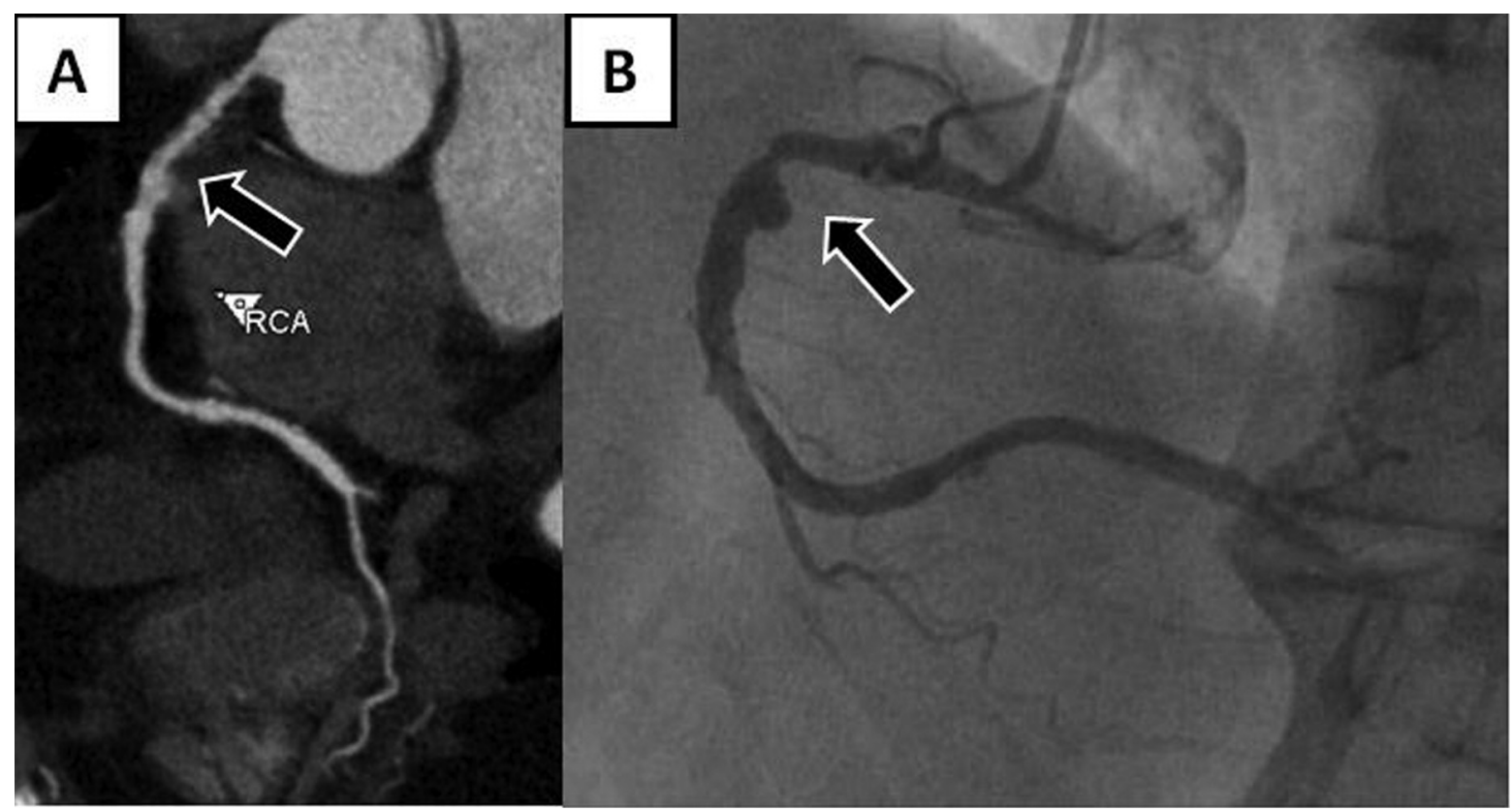

Gambar 3 atau 4. Analisis stenosis underestimate pada laki-laki usia 60 tahun di RCA.

A: Lesi stenosis dari CTA dengan derajat stenosis sedang (50\%).

B: Lesi stenosis dari ICA dengan derajat stenosis berat (90\%).

yang tidak berbeda, yaitu $78.3 \%$. Rincian data plak berkalsifikasi yang ditemukan pada berbagai klasifikasi perbandingan analisis semi-kuantitatif dapat dilihat pada Tabel 4.

Tabel 4. Hubungan perbandingan penilaian derajat stenosis antara $C T A$ dengan ICA dan keberadaan plak berkalsifikasi dalam pembuluh koroner $(p=0,102)$

\begin{tabular}{ll}
\hline $\begin{array}{l}\text { Plak berkalsifikasi pada klasifikasi stenosis } \\
\text { semi-kuantitatif }\end{array}$ & $\mathrm{N}(\%)$ \\
\hline $\begin{array}{l}\text { Terdapat plak berkalsifikasi } \\
\text { Concordance }\end{array}$ & $132(29.53)$ \\
Overestimate & $217(48.55)$ \\
Underestimate & $98(21.92)$ \\
Tidak terdapat plak berkalsifikasi & \\
Concordance & $35(27.78)$ \\
Overestimate & $52(41.27)$ \\
Underestimate & $39(30.95)$ \\
\hline
\end{tabular}

\section{Diskusi}

Hasil akurasi diagnostik penelitian ini menunjukkan sensitivitas dan spesifisitas pemeriksaan CTA sebesar $81.4 \%$ dan $80.4 \%$ dalam mendeteksi lesi obstruktif di pembuluh koroner. Sensitivitas dan spesifisitas pada penelitian ini lebih rendah dari penelitian-penelitian sebelumnya. ${ }^{6-10}$ Pedoman penyakit jantung koroner stabil tahun 2013 yang dipublikasikan oleh ESC menyatakan bahwa CTA dapat diandalkan untuk deteksi lesi obstruktif pada pembuluh koroner dengan sensitivitas dan spesifisitas mencapai $95-99 \%$ dan 64-83\%. ${ }^{5}$ Terdapat perbedaan angka yang mencolok. Salah satu penyebab perbedaan tersebut adalah perbedaan populasi subjek penelitian. Penelitian ini bukan merupakan studi diagnostik murni, dimana populasi penelitian merupakan pasien-pasien dengan kecurigaan klinis penyakit jantung koroner. Penelitian ini menggunakan populasi pasien dengan kecurigaan klinis penyakit jantung koroner yang teridentifikasi memiliki lesi obstruktif pembuluh koroner berdasarkan pemeriksaan CTA. Jika penelitian ini memasukkan populasi pasien dengan kecurigaan klinis penyakit jantung koroner namun telah terbukti tidak ada lesi obstruktif, angka sensitivitas penelitain ini akan jauh lebih tinggi. Lebih jauh lagi, analisis statistik pemeriksaan diagnostik pada penelitian-penelitian sebelumnya menggunakan patient-based analysis. ${ }^{6-7}$ Sementara penelitian ini menggunakan vessel-based analysis. Perbedaan metode analisis statistik ini juga berdampak memberikaan perbedaan angka yang mencolok. 


\section{Haykal TM dkk: Presisi Computed Tomography Angiography Terhadap Invasive Angiography pada masing-masing}

Pembuluh Koroner: Overestimate, Underestimate, atau Concordance?

Terdapat perbedaan akurasi pada pembuluh koroner yang berbeda pada penelitian ini. Hasil perbandingan analisis stenosis pada LM terutama overestimate. Sementara hasil perbandingan analisis stenosis pada LAD terutama concordance. Pada beberapa penelitian sebelumnya, ketidakakuratan analisis stenosis dari pemeriksaan CTA adalah diakibatkan oleh lesi plak berkalsifikasi. ${ }^{8}$ Namun tidak demikian pada penelitian ini, dimana telah dianalisis secara statistik bahwa lesi plak berkalsifikasi tidak berbeda secara signifikan. Analisis stenosis LM yang didominasi oleh kategori overestimate dicurigai diakibatkan karena pada umumnya tidak terdapat referensi pembuluh darah yang baik untuk menentukan derajat lesi stenosis. ${ }^{13-}$ ${ }^{14} \mathrm{Hal}$ ini dipengaruhi struktur LM yang pendek. Perbedaan yang ditemukan pada pembuluh koroner lainnya dicurigai disebabkan oleh perbedaan anatomi koroner, baik dari ukuran, morfologi, ataupun segmen koroner. ${ }^{13-14}$

Penelitian ini memiliki beberapa keterbatasan. Pertama, penilaian kuantifikasi stenosis tidak menggunakan pengukuran objektif yang hasil pengukurannya lebih pasti. Hal ini dikarenakan bahwa penelitian ini bertujuan untuk mencerminkan keseharian praktik klinik pencitraan kardiovaskuler sehari-hari yang menggunakan penilaian derajat stenosis secara visual. Kemudian, penelitian ini tidak membedakan karakteristik anatomis pembuluh koroner, dari segi diameter dan segmentasinya. Lesi pada bagian proksimal cenderung memiliki nilai akurasi yang lebih tinggi. Namun penelitian ini tidak dapat menilai hal tersebut. ${ }^{15}$ Salah satu keterbatasan lain dalam penelitian ini adalah bahwa penelitian ini tidak menganalisis intraobserver dan interobserver agreement. Dan terakhir, penelitian ini tidak melakukan analisis perbedaan kualitas CTA, yang umumnya merupakan poin yang ditekankan dalam penelitian mengenai $C T A$.

\section{Kesimpulan}

Penelitian ini merupakan penelitian sederhana yang berupaya menggambarkan analisis stenosis yang dilakukan sehari-hari dalam praktik klinis pencitraan kardiovaskular. Dari total 195 pasien, ditemukan bahwa penilaian derajat stenosis menggunakan CTA terutama overestimate pada LM. Presisi stenosis dari angiografi $M D C T$ tidak sama pada tiap pembuluh koroner.

\section{Daftar Singkatan}

CTA: Computed Tomography Angiography

ICA: Invasive Coronary Angiography

LAD: Left Anterior Descending coronary artery

LCX: Left Circumflex coronary artery

LM: Left Main coronary artery

MDCT: Multi-Detector Computed Tomography

NPV: Negative Predictive Value

PPV: Positive Predictive Value

RCA: Right Coronary Artery

RSJPDHK: Rumah Sakit Jantung dan Pembuluh Darah Harapan Kita

SCCT: Society of Cardiovascular Computed Tomography

\section{Daftar Pustaka}

1. Alfakih K, Budoff M. MDCT coronary angiography: does the benefit justify radiation burden? Br J Cardiol. 2010; 17: 207-8.

2. Bluemke DA, Achenbach S, Budoff M, Gerber TC, Gersch B, et al. Noninvasive coronary artery imaging: magnetic resonance angiography and multidetector computed tomography angiography: a scientific statement from the american heart association committee on cardiovascular imaging and intervention of the council on cardiovascular radiology and intervention, and the councils on clinical cardiology and cardiovascular disease in the young. Circulation. 2008; 118(5): 586-606.

3. Leipsic J, Abbara S, Achenbach S, Cury R, Earls JP, et al. SCCT guidelines for the interpretation and reporting of coronary $\mathrm{CT}$ angiography: a report of the society of cardiovascular computed tomography guideines committee. J Cardiovasc Comput Tomogr. 2014; 8(5): 342-58.

4. Zadeh AA, Hoe J. Quantificatin of coronary arterial stenoses by multidetector CT angiography in comparison with conventional angiography. J Am Coll Cardiol Img. 2011; 4: 191-202.

5. Montalescot G, Sechtem U, Achenbach S, Andreotti F, Arden C, et al. 2013 ESC guidelines on the management of stable coronary artery disease: the Task Force on the management of stable coronary artery disease of the European Society of Cardiology. Eur Heart J. 2013; 34(38): 2949-3003.

6. Mollet NR, Cademartiri F, Nieman K, Saia F, Lemos PA, et al. Multislice spiral computed tomography coronary angiography in patients with stable angina pectoris. J Am Coll Cardiol. 2004; 43: 2265-70.

7. Meijboom WB, Meijs MFL, SchuijfJD, Cramer MJ, Mollet NR, et al. Diagnostic accuracy of 64-slice computed tomography coronary angiography. J Am Coll Cardiol. 2008; 52: 2135-44. 
8. Zhang S, Levin DC, Halpern EJ, Fischman D, Savage M, et al. Accuracy of MDCT in assessing the degree of stenosis caused by calcified coronary artery plaques. Am J Roentgenol. 2008; 191(6): 1676-83.

9. Leschka S, Alkadhi H, Plass A, Desbiolles L, Grunenfelder J, et al. Accuracy of MSCT coronary angiography with 64-slice technology: first experience. Eur Heart J. 2005; 26(15): 1482-7.

10. Pugliese F, Mollet NR, Runza G, Mieghem C, Meijboom WB, et al. Diagnostic accuracy of non-invasive 64-slice CT coronary angiography in patients with stable angina pectoris. Eur Radiol. 2006; 16: 575-82.

11. Raff GL, Gallagher MJ, O'neill WW, Goldstein JA. Diagnostic accuracy of noninvasive coronary angiography using 64-slice spiral computed tomography. J Am Coll Cardiol. 2005; 46: 552-7.

12. Dodd JD, Rieber J, Pomerantsev E, Chaithiraphan V, Achenbach $S$, et al. Quantification of nonculprit coronary lesions: comparison of cardiac 64-MDCT and invasive coronary angiography. Am J Roentgenol. 2008; 191: 432-8.

13. Nikolau K, Knez A, Rist C, Wintersperger BJ, Leber A, et al. Accuracy of 64-MDCT in the diagnosis of ischemic heart disease. Am J Roentgenol. 2006; 187: 111-7.

14. Leta R, Carreras F, Alomar X, Monell J, Picart JG, et al. Noninvasive coronary angiography with 16 multidetector-row spiral computed tomography: a comparative study with invasive coronary angiography. Rev Esp Cardiol. 2004; 57(3): 217-24.
15. Meijer AB, O YL, Geleijns J, Kroft LJ. Meta-analysis of 40- and 64-MDCT angiography for assessing coronary artery stenosis. Am J Roentgenol 2008; 191(6): 1667-75.

\section{Persetujuan Etik}

Penelitian ini adalah hasil karya sendiri, dan semua sumber yang dikutip maupun dirujuk telah dinyatakan dengan benar dan telah lolos kaji etik

\section{Persetujuan untuk Publikasi}

Semua pihak telah menyetujui publikasi penelitian ini.

\section{Konflik Kepentingan}

Tidak ada konflik kepentingan dalam pelaksanaan penelitian ini.

\section{Pendanaan}

Pendanaan penelitian ini berasal dari dana pribadi peneliti. 